\title{
The question of "equality" in freedom of religion in Vietnam
}

S. N. Nguyen ${ }^{1}$

${ }^{1}$ Law Institute, Peoples' Friendship University of Russia, 6, 246, Miklukho-Maklaya str., Moscow 117198, Russian Federation

DOI: 10.18255/1996-5648-2021-3-418-421

Research article Full text in Russian

The article is about how step by step, religious equality has become a solution in the process of ensuring religious freedom in the environment of religious pluralism and religious diversity. However, around the application of the equality solution, there have been arguments about its practical effectiveness. This article illustrates observations about equality in religious freedom in Vietnam, which are based on scientific methods: analysis, synthesis, and comparison. The research results confirm that the equal solution has proved consistent with the characteristics of the Vietnamese socialist state and Vietnamese culture tolerance and posed challenges to recognizing religious organizations' legal status in Vietnam.

Keywords: religion; freedom; equality; tolerance; culture

\section{INFORMATION ABOUT AUTHORS}

\begin{tabular}{l|l} 
Nguyen, Son Nam & $\begin{array}{l}\text { E-mail: sonnamnguyen0212@gmail.com } \\
\text { Postgraduate }\end{array}$
\end{tabular} 


\title{
Вопрос о "равенстве» в свободе вероисповедания во Вьетнаме
}

\author{
Ш. Н. Нгуен ${ }^{1}$
}

${ }^{1}$ Юридический институт, Российский университет дружбы народов, ул. Миклухо-Маклая д. 6, 246, Москва, 117198, Российская Федерация

DOI: $10.18255 / 1996-5648-2021-3-418-421$

Удк 348.01/.07

Научная статья

Полный текст на русском языке

Шаг за шагом идея религиозного равенства стала решением в процессе обеспечения свободы вероисповедания при условии религиозного плюрализма и разнообразия. Однако вокруг применения данного решения были споры о его практической эффективности. В статье иллюстрируются наблюдения о равенстве в религиозной свободе во Вьетнаме, основанные на научных методах: анализе, синтезе и сравнении. Результаты исследования подтверждают, что утверждение равенства не только соответствует характеристикам вьетнамского социалистического государства и вьетнамской толерантной культуры, но и создает проблемы для признания правового статуса религиозных организаций во Вьетнаме.

Ключевые слова: религия; свобода; равенство; толерантность; культура ИНФОРМАЦИЯ ОБ АВТОРАХ

$$
\begin{array}{l|l}
\text { Нгуен, Шон Нам } & \begin{array}{l}
\text { E-mail: sonnamnguyen0212@gmail.com } \\
\text { Аспирант }
\end{array}
\end{array}
$$

Исследование Ф. М. Гедикса показало, что после сохранения религиозного разнообразия в какой-то момент государству приходится идти на переговоры с местными жителями, используя в равной степени бесчисленные разновидности религиозных убеждений [1]. Поэтому, по его мнению, равенство между конфессиями рассматривается как оптимальное решение для правительств в решении проблемы свободы вероисповедания. В результате данного процесса либеральные демократии Запада изменили свой основной переход от свободы к равенству. Если поместить этот вопрос во вьетнамский контекст, можно увидеть, что три важных вопроса заключаются в следующем.

Во-первых, выражение "равенства» в законодательстве о свободе вероисповедания во Въетнаме.

Во Вьетнаме существует юридическое признание равенства конфессий, независимо от количества верующих конфессий. "Равенство» было в основном отмечено в Указе Президента Демократической Республики Вьетнам № 234 от 14.06.1955 о религиозных вопросах: «религиозные организации, а также все другие народные организации должны соблюдать законы Демократической Республики Вьетнам» (ст. 14). Вопрос о равенстве между религиями был одобрен в Постановлении Правительственного Совета Социалистической Республики Вьетнам № 297 от 11.11.1977

(C) Нгуен Ш. Н., 2021

Статья открытого доступа под лицензией CC BY (https://creativecommons.org/licenses/by/4.0/) 
Нгуен Ш. Н.

«О политике в отношении религии», упомянутого в пункте 3 раздела I: «Все религии равны перед законом». После этого он был продублирован в статье 70 Конституции Вьетнама от 15.04.1992 и затем сохранен в следующих юридических документах: в Постановлении Постоянного комитета Национального собрания Социалистической Республики Вьетнам № 21 от 18.06.2004 «О вероисповедании» (ст. 1); Конституции Вьетнама от 28.11.2013 (ст. 24); Законе Национального собрания Социалистической Республики Вьетнам № 02 от 18.11.2016 «О вероисповедании» (ст. 3).

Во-вторъх, уместность решения «равенства» во въетналском обществе.

«Равенство» имеет отношение с нейтралитетом вьетнамского государства в религиозных вопросах. По мнению Б. Хайнера, равенство «прежде всего означает недискриминацию» и одним из его условий является то, что «государство должно быть нейтральным в том смысле, что оно не отождествляет себя с какой-либо конкретной религией или убеждением» [2]. Более того, по мнению большинства вьетнамских ученых, сохранение принципа "равенства» представляется приемлемым для вьетнамского общества, поскольку вьетнамское государство с «нерелигиозными марксистскими взглядами» является «благоприятным условием» для обеспечения объективного и равного отношения ко всем конфессиям [3, с. 31]. С одной стороны, нейтралитет государства в религиозных вопросах является традицией Вьетнама. Вьетнам - страна без государственной религии. В истории Вьетнама, хотя и было время, когда королевское государство отдавало приоритет буддизму или конфуцианству, вьетнамские исследователи признавали, что даже в те периоды эти религии не были государственной религией [4]. С другой стороны, одним из необходимых проявлений нейтралитета государства в отношениях с конфессиями является «отказ от вмешательства во внутренние дела конфессий». Довольно долгое время во Вьетнаме религиозная политика устанавливала и реализовывала принцип "невмешательства». В Указе Президента Демократической Республики Вьетнам № 234 от 14.06.1955 о религиозных вопросах определено: «Правительство не вмешивается во внутренние дела религий. Что касается католицизма, религиозные отношения между Вьетнамской церковью и Римским Святым Престолом - это внутренний вопрос католицизма».

«Равенство» тесно связано с культурой толерантности во Вьетнаме. Культура толерантности неразрывно связана с вьетнамскими национальными традициями. До трансформации с западной культурой традиционная культура Вьетнама несла в себе признаки толерантности, благодаря которой буддизм, конфуцианство и даосизм мирно сосуществовали на протяжении веков, несмотря на их различия. На протяжении многих веков три основные импортированные религии, а именно буддизм, даосизм и конфуцианство, даже сочетались с народными верованиями и были локализованы в одну значительную синкретическую религию, называемую «тройной религией», которая является типичной чертой традиционного вьетнамского общества [5, с. 217]. Вьетнамский народ, обладающий толерантной культурой, принял все конфессии. Толерантное поведение подпитывается принципом «равенства» в культурных традициях вьетнамского народа. Все религии независимо от того, много или мало верующих, независимо от их долгой или короткой истории, могут жить вместе в гармонии в культурной среде Вьетнама.

В-третьих, проблемы при обеспечении "равенства».

Обеспечение равенства - действительно многогранная задача как для восточных, так и для западных стран. Это не означает, что эти страны не прилагают ни- 
Вопрос о «равенстве» в свободе вероисповедания...

каких усилий, но они исходят из проблемы большой сложности в стремлении достичь абсолютного равенства. Во Вьетнаме характер светской модели государства состоит в том, чтобы следовать направлению поддержки религиозного разнообразия. [4]. По сути, государство выборочно признает религиозные организации и обеспечивает равенство для всех остальных религий. Однако из-за «регистрационной» формы равенство религий перед законом столкнется с проблемой «отказа признать правовой статус» для «новых религиозных явлений» или "небольших религиозных групп». В. К. Дарем утверждает, что существует слишком много проблем для религиозной группы, нуждающейся в «законной религиозной деятельности» без юридического статуса [6, с. 60]. Однако во Вьетнаме среди религиозных объединений, требующих признания юридического статуса, немало «религий малых групп» и «новых религиозных явлений» со странными верованиями, наносящими вред общественному здоровью [7]. Признание данных объединений приведет к «дискриминации» признанных религиозных организаций. Поэтому необходимо создать надлежащую правовую базу для регулирования новых религиозных явлений [8, с. 153].

Следовательно, не нужно абсолютизировать роль "равенства». С. Феррари изучает европейское пространство и утверждает, что нет единого ответа на вопрос обэффективностипереходаотсвободыкравенству,потомучтоданнаяэффективность зависит от контекста, в котором он происходит, и его влияние различается в разных национальных правовых системах [9]. М. Д. Розен также согласен с С. Феррари в том, что правильность и неправильность решения “равенства» следует рассматривать с точки зрения роли различных государственных институтов (например, судов, законодательных органов, исполнительной власти) и даже роли граждан и других частей гражданского общества в защите свободы вероисповедания [10, с. 140].

\section{Ссылки}

1. Gedicks F. M. Religious Freedom as Equality // Routledge Handbook of Law and Religion / Silvio Ferrari (ed.). London: Routledge, 2015. P. 133-144.

2. Heiner B. Freedom of Religion or Belief - A Human Right under Pressure // Oxford Journal of Law and Religion. 2012. № 1. P.15-35.

3. До К. Х. Проблема признания религиозных организаций - Сравнительный подход: на примере Вьетнама // Журнал религиоведения. 2007. № 1. С. 24-34.

4. До К. Х. Государство - Религия - Закон. Ханой: Национальное политическое издательство, 2015. 455 с.

5. Hoang V. N. Religious Diversity, and the Right to Freedom of Religion in Vietnam Today // Academic Journal of Interdisciplinary Research. 2015. № 4. P. 213-222.

6. Durham W. C. Evolution and Current Context of Religion Laws in Southeast Asia: A Comparative Perspective // Journal of Religious Studies. 2007. № 1. P. 60-68.

7. Нгуен Х. З. Проблемы религиозного разнообразия во Вьетнаме на сегодня // Журнал религиоведения. 2015. № 10. С. 3-30.

8. Hoang V. C. New Religions and State's Response to Religious Diversification in Contemporary Vietnam - Tensions from the Reinvention of the Sacred. Cham: Springer International Publishing, 2017. 176 p.

9. Ferrari S. Religion between Liberty and Equality // Journal of Law. Religion and State. 2016. № 4. P. 179-193.

10. Rosen M. D. Two Ways of Conceptualizing the Relationship between Equality and Religious Freedom // Journal of Law. Religion and State. 2016. № 4. P. 117-145. 